\title{
Salidroside suppresses the metastasis of hepatocellular carcinoma cells by inhibiting the activation of the Notch1 signaling pathway
}

\author{
LINLIN LU ${ }^{1 *}$, SHOUSHENG LIU ${ }^{2,3 *}$, QUANJIANG DONG ${ }^{2}$ and YONGNING XIN YN-5 $^{3-5}$ \\ ${ }^{1}$ Department of Clinical Medicine, Qingdao University, Qingdao University Hospital, Qingdao, Shandong 266003; \\ ${ }^{2}$ Central Laboratories, Qingdao Municipal Hospital; ${ }^{3}$ Digestive Disease Key Laboratory of Qingdao, Qingdao, \\ Shandong 266071; Departments of ${ }^{4}$ Gastroenterology and ${ }^{5}$ Infectious Disease, \\ Qingdao Municipal Hospital, Qingdao, Shandong 266011, P.R. China
}

Received July 17, 2018; Accepted March 26, 2019

DOI: $10.3892 / \mathrm{mmr} .2019 .10115$

\begin{abstract}
Salidroside (SDS) is a phenylpropanoid glycoside isolated from Rhodiola rosea L. It exhibits multiple pharmacological properties in clinical medicine and has been commonly used in traditional Chinese medicine. The present study investigated the inhibitory effects of SDS on tumor invasion and migration, and the expression of metastasis-related genes in highly metastatic hepatocellular carcinoma (HCC) cells $(\mathrm{MHCC} 97 \mathrm{H})$ in vitro. The underlying mechanisms of SDS on the tumor metastasis were also explored. SDS was found to significantly reduce wound closure areas and inhibit cell migration. In addition, SDS markedly inhibited the invasion of these cells into Matrigel-coated membranes. SDS markedly downregulated the expression of Notchl, Snail, COX-2, MMP-2, MMP-9 genes and upregulated the expression of $E$-cadherin in a dose-dependent manner. Furthermore, SDS inhibited the expression of the Notch signaling target genes, Heyl, Hesl and Hes5. On the whole, the findings of this study suggest that SDS inhibits HCC cell metastasis by modulating the activity of the Notch1 signaling pathway.
\end{abstract}

\section{Introduction}

Hepatocellular carcinoma (HCC) is the most commonly diagnosed primary tumor of the liver, ranking third worldwide in terms of the most lethal types of cancer $(1,2)$. While there are some treatment options available for patients, such as surgical intervention, radiotherapy, locoregional therapy and chemotherapy, the rates of metastasis and relapse remain high for

Correspondence to: Dr Yongning Xin, Department of Infectious Disease, Qingdao Municipal Hospital, 1 Jiaozhou Road, Qingdao, Shandong 266011, P.R. China

E-mail: xinyongning@163.com

"Contributed equally

Key words: salidroside, hepatocellular carcinoma, migration, invasion, Notch1 signaling pathway patients with HCC $(3,4)$. Therefore, there is currently an urgent need for improved treatment options in clinical practice.

Salidroside (SDS) acts as a phenylpropanoid glycoside and is one of the most potent antioxidant ingredients that can be isolated from Rhodiola rosea L. It commonly grows at high altitudes and may be found in parts of Asia, Eastern Europe and Canada $(5,6)$. SDS functions as an adaptogen that provides non-specific resistance by suppressing physical, chemical and biological stressors in the body, and has been used as a hepato-protective herb in traditional Chinese medicine for decades (5).

In recent years, SDS has been reported to possess numerous medicinal properties, including antitumor, anti-inflammatory, anti-viral, anti-radiation, antioxidative stress and fatigue-reducing properties (7-16). Most notably, the anticancer properties of SDS have been extensively reported by researchers in both in vitro and in vivo models. SDS has been shown to significantly inhibit the growth of lung, breast and liver cancer through the promotion of the activation of cellular apoptotic pathways, and to inhibit breast tumor growth in vivo (6,17-22). In addition, SDS has been shown to inhibit metastasis, as Sun et al demonstrated that SDS inhibited the migration and invasion of HT1080 human fibrosarcoma cells (23). However, there is limited information about the role of SDS in preventing the metastasis in other forms of cancer, and its underlying mechanisms of action remain unknown.

Notch signaling is highly conserved and is often activated in many types of tumors, playing complex roles in tumor development and metastasis (24-30). Previously, Zhou et al (31) reported Notch1 as a novel candidate biomarker for assessing patient prognosis, as well as for the molecular targeted therapy of HCC. This is due to the high expression of Notch1 in HCC tumor tissues, which has been associated with tumor size, tumor grade, metastasis, venous invasion and TNM stage. Patients with a high Notch1 expression were shown to have significantly shorter overall survival times (31).

The downregulation of Notch1 has been previously found to decrease the invasiveness of HCC cells in vitro (32), which is partially attributed to the activation of the Notch1/Snail/ E-cadherin pathway (33-36). E-cadherin acts as a homotypic epithelial cell-cell adhesion molecule with anti-invasive properties in certain types of cancer (37-39). The Notch1/matrix metalloproteinase (MMP) pathway has also been found to play 
an important role in HCC development, as MMPs are proteolytic enzymes in the extracellular matrix (ECM) that contribute to tumor invasion, angiogenesis and metastasis (40-42). Previously, the downregulation of Notch1 in pancreatic cancer and lingual squamous cell carcinoma was shown to inhibit tumor invasion by suppressing the expression of MMP-2 and MMP-9 $(28,29,32)$. In addition, an inhibitor of the Notch signaling pathway effectively inhibited the invasion of HCC cells via MMP-2 and MMP-9 suppression (32), confirming that the Notch1 signaling is closely associated with the metastasis of HCC.

In the present study, we demonstrate that SDS suppresses the metastasis of highly metastatic HCC cells. Genes involved in EMT and metastasis are consisted regulated. Notably, Notch1 signaling activity is inhibited by SDS. Taken together, the findings of this study suggest that SDS suppresses the metastasis of HCC cells through suppression of the activation of the Notch1 signaling pathway.

\section{Materials and methods}

Reagents and antibodies. SDS (purity, >99\%) was purchased from the National Institute for the Control of Pharmaceutical and Biological Products (Beijing, China). SDS was dissolved in water and filtered through a $0.22-\mu \mathrm{m}$ filter prior to use. Hairy and enhancer of split 1 (Hes1; cat. no. BM4488) polyclonal antibodies were purchased from Boster Biological Co. (Wuhan, China). Hairy/enhancer-of-split related with YRPW motif 1 (Hey1; cat. no. 19929-1-AP) and hairy and enhancer of split 5 (Hes5; cat. no. 22666-1-AP) polyclonal antibodies were purchased from ProteinTech Biological Co. (Wuhan, China). Cyclooxygenase (COX)-2 (cat. no. KGYT1073-6), E-cadherin (cat. no. KGYT1453-6), MMP-2 (cat. no. KGYT2798-6) and MMP-9 (cat. no. KGYT1892-6) polyclonal antibodies were purchased from KeyGEN BioTech Corp. (Nanjing, China). Snail (cat. no. bs-21598R) and Notch1 (cat. no. bs-1335R) polyclonal antibodies were purchased from Bioss Biological Co. (Beijing, China). DMEM was purchased from the Gibco; Thermo Fisher Scientific Inc. (Waltham, MA, USA). FBS was purchased from the ExCell Biology Company (Shanghai, China). All other chemicals were of analytical grade and were commercially available.

Cells and cell culture. The MHCC97H cells (cat. no. KG340) were obtained from KeyGEN BioTech Corp. the HMCC97H cells were cultured in DMEM supplemented with $10 \%$ fetal bovine serum (FBS) in a humidified incubator at $37^{\circ} \mathrm{C}$ with $5 \% \mathrm{CO}_{2}$. The cells were harvested following trypsinization (0.25\% Trypsin-EDTA) and washed with phosphate-buffered saline (PBS). The cells were subcultured when the cell density reached $80-90 \%$ confluency.

Scratch wound closure assay. For the detection of cell migration, the HMCC97H cells were seeded onto a 6-well plate and cultured at $37^{\circ} \mathrm{C}$ for $24 \mathrm{~h}$. When the cell density reached $60 \%$ confluency, the monolayer was scraped away with a sterile tip, as previously described (43). The remaining cells were washed with PBS, and cultured with new medium with 1,2 , or $4 \mu \mathrm{g} / \mathrm{ml}$ of SDS at $37^{\circ} \mathrm{C}$ for $24 \mathrm{~h}$. Cell migration into the denuded area was quantified using a computer-assisted inverted microscope (IX71; Olympus Corporation, Tokyo, Japan; magnification, x200).
Transwell assay for in vitro migration. HMCC97H cell migration was measured using Matrigel-coated Transwell inserts. The cells were cultured in serum-free DMEM at $37^{\circ} \mathrm{C}$ for $24 \mathrm{~h}$ before being trypsinized and seeded at $5 \times 10^{4}$ cells per upper chamber in $100 \mu \mathrm{l}$ serum-free DMEM with 1,2 or $4 \mu \mathrm{g} / \mathrm{ml}$ SDS. The 24-well plate containing the Transwell was cultured in a humidified incubator at $37^{\circ} \mathrm{C}$ and $5 \% \mathrm{CO}_{2}$ for $24 \mathrm{~h}$. Cells in the upper side of the insert membrane were rubbed using a cotton swab. Cells that had migrated to the underside of the insert membrane were stained with $0.1 \%$ crystal violet solution for $30 \mathrm{~min}$ at $37^{\circ} \mathrm{C}$, rinsed in PBS, air-dried, and observed under an inverted microscope (IX71; Olympus Corporation) equipped with a camera to count the number of migrated cells (magnification, $\mathrm{x} 200$ ). Three fields per insert were scored and averaged.

In vitro invasion assay. The invasion of the $\mathrm{HMCC} 97 \mathrm{H}$ cells in vitro was determined using Matrigel-coated Transwell inserts, as previously described (44). Serum-free DMEM with 2-fold diluted Matrigel (30 $\mu \mathrm{l} /$ well) was placed into the upper chamber of the Transwell filter and incubated for $2 \mathrm{~h}$ at $37^{\circ} \mathrm{C}$ for gelling. Subsequently, $5 \times 10^{4}$ cells were seeded in the upper chamber and cultured at $37^{\circ} \mathrm{C}$ for $24 \mathrm{~h}$. The invasion of the cells was assessed using the same techniques as those used for cell migration described above.

Reverse transcription-quantitative PCR (RT-qPCR). RT-qPCR was used to determine the expression levels of Notchl, Hes1, Hes5, Heyl, COX-2, Snail and E-cadherin in the SDS-treated HMCC 97H cells. The cells were incubated with serum-free DMEM containing 1, 2 or $4 \mu \mathrm{g} / \mathrm{ml}$ SDS for $24 \mathrm{~h}$. Subsequently, the cells were trypsinized, washed in PBS, and total RNA was extracted using TRIzol reagent (Thermo Fisher Scientific Inc.) according to the manufacturer's instructions. First-strand cDNA was synthesized with a reverse transcription kit (Thermo Fisher Scientific Inc.) according to the manufacturer's instructions and used as the template for RT-qPCR. GAPDH was selected as the reference for internal standardization. The primers P1 and P2 specific of GAPDH, P3 and P4 specific of Hes1, P5 and P6 specific of Hes5, P7 and P8 specific of Heyl, P9 and P10 specific of COX-2, P11 and P12 specific of Snail, P13 and P14 specific of $M M P-2, \mathrm{P} 15$ and P16 specific of $M M P-9$, and P17 and P18 specific of E-cadherin (Table I) were designed to amplify the specific fragments of all the genes. qPCR was performed on an ABI 7500 real-time PCR system (Applied Biosystems, Foster City, CA, USA) using the 2X SYBR Premix Ex Taq $^{\mathrm{TM}}$ kit (Takara, Shiga, Japan). PCR was carried out in a total volume of $20 \mu \mathrm{l}$, containing $10 \mu \mathrm{l} 2 \mathrm{X}$ SYBR Premix Ex Taq $^{\mathrm{TM}}, 0.4 \mu \mathrm{l}$ ROX Reference Dye II (50X), $1 \mu$ l diluted cDNA, $0.2 \mu \mathrm{l}$ primers $(20 \mathrm{mmol} / \mathrm{l})$ and $8.4 \mu \mathrm{l}$ of DEPC-treated water. The thermal profile for RT-qPCR was $94^{\circ} \mathrm{C}$ for $15 \mathrm{sec}$, followed by 40 cycles of $94^{\circ} \mathrm{C}$ for $5 \mathrm{sec}, 60^{\circ} \mathrm{C}$ for $15 \mathrm{sec}$ and $72^{\circ} \mathrm{C}$ for 35 sec. All reactions were run in triplicate. Dissociation curve analysis of the amplicons was performed at the end of each PCR to confirm that only one PCR product was amplified and detected. Data were analyzed with the comparative $\mathrm{Cq}$ method $\left(2^{-\triangle \Delta \mathrm{Cq}}\right)$ based on $\mathrm{Cq}$ values for each gene and $G A P D H$ to calculate relative mRNA expression levels (45).

Western blot analysis. The HMCC97H cells were cultured with serum-free DMEM with 1,2 , or $4 \mu \mathrm{g} / \mathrm{ml} \mathrm{SDS} \mathrm{for}$ 
Table I. Table I. Sequences of the primers used in this study.

\begin{tabular}{|c|c|c|}
\hline Gene & Sequence $\left(5^{\prime}-3^{\prime}\right)$ & Amplicon size (bp) \\
\hline \multirow[t]{2}{*}{ Notchl } & F-TCAGCGGGATCCACTGTGAG & \\
\hline & R-ACACAGGCAGGTGAACGAGTTC & 104 \\
\hline \multirow[t]{2}{*}{ Hesl } & F-CTGAGCACAGACCCAAGTGT & \\
\hline & R-GAGTGCGCACCTCGGTATTA & 115 \\
\hline \multirow[t]{2}{*}{ Hes 5} & F-GAAAAACCGACTGCGGAAGC & \\
\hline & R-GACGAAGGCTTTGCTGTGCT & 184 \\
\hline \multirow[t]{2}{*}{ Heyl } & F-CGGCTCTAGGTTCCATGTCC & \\
\hline & R-GCTTAGCAGATCCCTGCTTCT & 162 \\
\hline \multirow[t]{2}{*}{$C O X-2$} & F-ATAACCCCGCCAAAAGGGG & \\
\hline & R-CTGAGTACCAGGTCTGCAGTG & 145 \\
\hline \multirow[t]{2}{*}{ Snail } & F-CGAGTGGTTCTTCTGCGCTA & \\
\hline & R-GGGCTGCTGGAAGGTAAACT & 160 \\
\hline \multirow[t]{2}{*}{$M M P-2$} & F-GATGACATCAAGGGCATTCAGGAGC & \\
\hline & R-ATCTTTTCCGGGAGCTCAGGCC & 254 \\
\hline \multirow[t]{2}{*}{$M M P-9$} & F-CCAAGGATACAGTTTGTTCCTCGTG & \\
\hline & R-GGTTCAGGGCGAGGACCATAGA & 177 \\
\hline \multirow[t]{2}{*}{ E-cadherin } & F-GTCAGTTCAGACTCCAGCCC & \\
\hline & R-TGTAGCTCTCGGCGTCAAAG & 196 \\
\hline \multirow[t]{2}{*}{$G A P D H$} & F-CATCTTCTTTTGCGTCGCCA & \\
\hline & R-TTAAAAGCAGCCCTGGTGACC & 202 \\
\hline
\end{tabular}

$24 \mathrm{~h}$. The cells were washed 3 times with ice-cold PBS and harvested in lysis buffer. The lysate was centrifuged at $12,000 \mathrm{x} g$ for $15 \mathrm{~min}$ to collect the supernatant. Bicinchoninic acid (BCA) was used to determine the protein concentrations. Subsequently, $40 \mu \mathrm{g}$ of each sample was loaded onto $12 \%$ sodium dodecyl sulfate (SDS)-polyacrylamide gels for electrophoresis and transferred onto nitrocellulose membranes. The membranes were blocked with $4 \%$ BSA in PBS at room temperature for $2 \mathrm{~h}$ prior to incubation with primary antibodies, which included anti-Notch1 $(1: 1,000)$, anti-Hey1 $(1: 1,000)$, anti-Hes1 $(1: 1,000)$, anti-Hes5 $(1: 1,000)$, anti-Snail $(1: 1,000)$, anti-COX2 (1:1,000), anti-E-cadherin (1:1,000), anti-MMP-2 (1:1,000), anti-MMP-9 (1:1,000), and anti-GAPDH $(1: 2,000)$. The membranes were incubated with the primary antibodies overnight at $4^{\circ} \mathrm{C}$ and washed 4 times with PBS containing 0.1\% Tween-20 (PBST). The membranes were then incubated with HRP-conjugated anti-mouse/rabbit IgG (cat. no. bs-0368R-HRP/bs-0369M-HRP; BIOSS, Beijing, China) diluted at 1:5,000 in PBS for $1 \mathrm{~h}$ at room temperature before being washed with PBS-T and detected using the ECL reagent (KeyGEN BioTech Corp.). The signal intensity of each band was quantified with Image J software (version 1.6.0; National Institutes of Health, Bethesda, MD, USA), and the results were normalized to those of GAPDH.

Statistical analysis. Data are presented as the means \pm standard errors of the mean (SEM) from 3 or more independent experiments and were evaluated with analysis of variance (ANOVA) followed by Dunnett's test for multiple comparisons. $\mathrm{P}<0.05$ was considered to indicate a statistically significant difference.

\section{Results}

SDS suppresses the migration of HMCC97H cells in vitro. The scratch test and Transwell assay were used to determine the effects of SDS on the migration of the HMCC97H cells. As shown in Fig. 1A, the wound closure was $69.2 \%$ complete in the absence of SDS. Following treatment with SDS, the wound closure levels were significantly lower at 58.2, 42.5 and $33.4 \%$ in the cells treated with 1,2 and $4 \mu \mathrm{g} / \mathrm{ml}$ SDS, respectively. The migration of the HMCC $97 \mathrm{H}$ cells was significantly suppressed by SDS, as shown by Transwell assay. As shown in Fig. 1B, cell migration was reduced to $65.31,39.68$ and $28.12 \%$ (relative to the control) following $24 \mathrm{~h}$ of treatment with 1,2 and $4 \mu \mathrm{g} / \mathrm{ml} \mathrm{SDS}$, respectively. These results demonstrated that SDS can effectively suppress HCC cell migration in a concentration-dependent manner.

SDS suppresses the invasion of HMCC97H cells in vitro. The Matrigel-coated Transwell assay was used to examine the effects of SDS on the invasion of the HMCC97H cells. As shown in Fig. 2, SDS treatment significantly suppressed the invasion of the HMCC97H cells in vitro. Following $24 \mathrm{~h}$ 

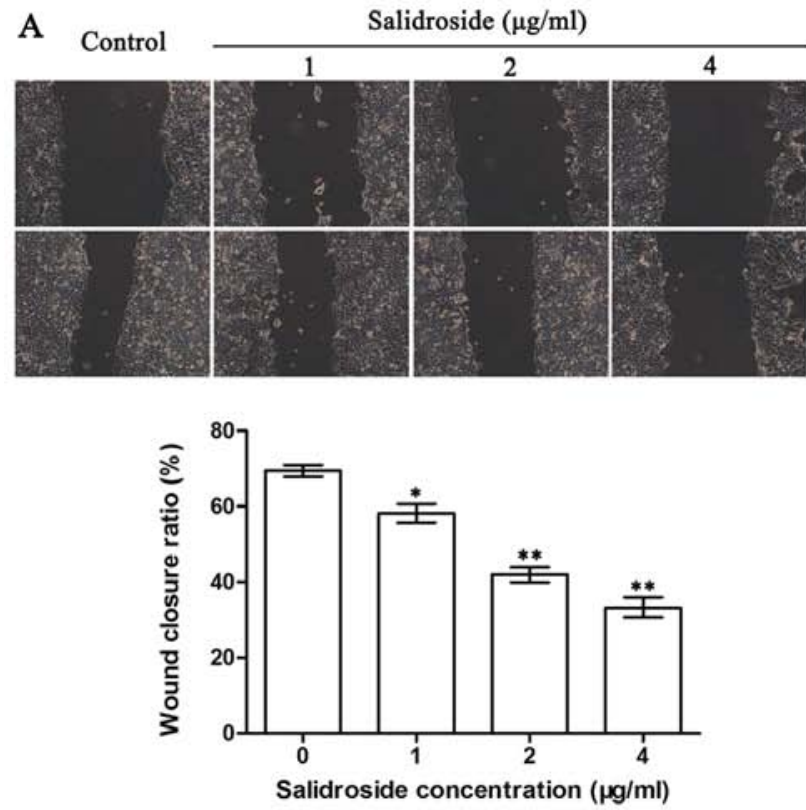

B
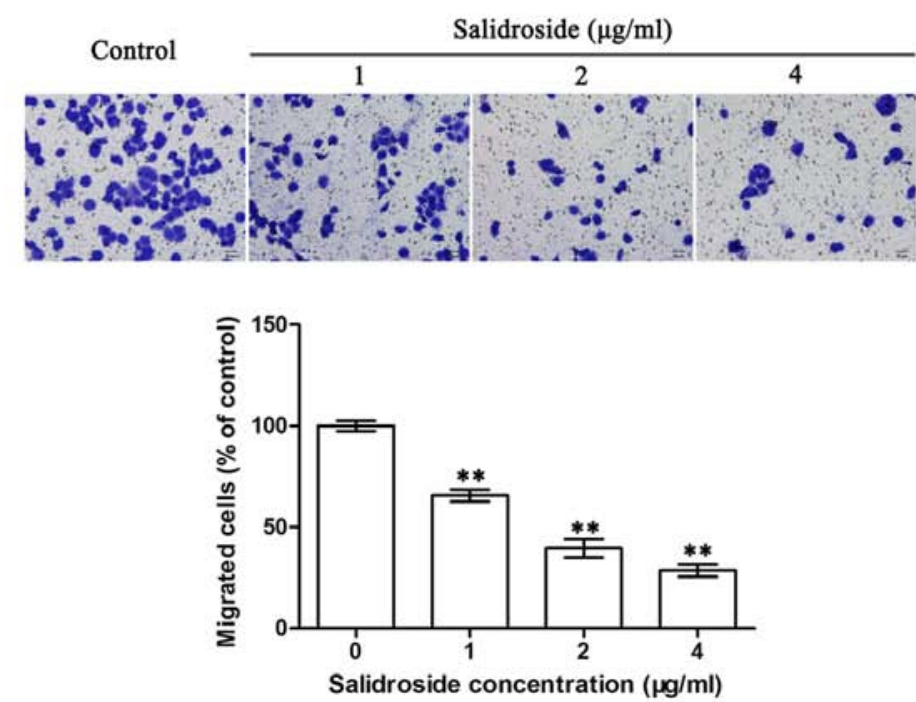

Figure 1. SDS suppresses the migration of HMCC97H cells in vitro. (A) The migration of the HMCC97H cells was quantified by measuring wound closure areas before and after injury. The wound closure areas were effectively reduced in the groups treated with 2 and $4 \mu \mathrm{g} / \mathrm{ml} \mathrm{SDS}$. (B) Cell migration was quantified under a microscope (magnification, $\mathrm{x} 200$ ). The numbers of migrated cells were significantly decreased in the groups treated with $1,2 \mathrm{and} 4 \mu \mathrm{g} / \mathrm{ml}$ SDS All data are presented as the means \pm SEM from 3 independent experiments. Asterisks indicate statistically significant differences $\left({ }^{*} \mathrm{P}<0.05\right.$ and $\left.{ }^{* *} \mathrm{P}<0.01\right)$ compared to the control $(0 \mu \mathrm{g} / \mathrm{ml})$. SDS, salidroside; SEM, standard error of the mean.



Figure 2. SDS suppresses the invasion of HMCC97H cells in vitro. The invasion of the HMCC97H cells was quantified by Matrigel-coated Transwell inserts. Images indicate the invaded cells visualized under a microscope (magnification, x200) following SDS treatment. The numbers of migrated cells were significantly decreased in the groups treated with 1,2 and $4 \mu \mathrm{g} / \mathrm{ml} \mathrm{SDS}$. All data are presented as the means \pm SEM from 3 independent experiments. Asterisks indicate statistically significant differences $\left({ }^{* *} \mathrm{P}<0.01\right)$ compared to the control $(0 \mu \mathrm{g} / \mathrm{ml})$. SDS, salidroside; SEM, standard error of the mean.

of treatment with SDS, the number of invaded cells had decreased to $64.5,29.0$ and $17.5 \%$ when treated with 1,2 and $4 \mu \mathrm{g} / \mathrm{ml}$ SDS, respectively. These results indicated that SDS effectively suppressed the invasion of the HMCC97H cells in a concentration-dependent manner.

SDS decreases the expression of Notchl, Snail, COX-2, MMP-2 and MMP-9, whereas it upregulates the expression of
E-cadherin in the HMCC97H cells. Western blot analysis was performed to investigate protein expression in the HMCC97H cells following treatment with SDS. Since Snail, COX-2, MMP-2, MMP-9 and E-cadherin are closely related to the metastasis of tumor cells $(43,46-48)$, we also investigated the effects of SDS on these genes in the HMCC97H cells. As shown in the Figs. 3 and 4, expression levels of Notchl, Snail, COX-2, MMP-2 and $M M P-9$ were significantly lower following treatment with SDS 

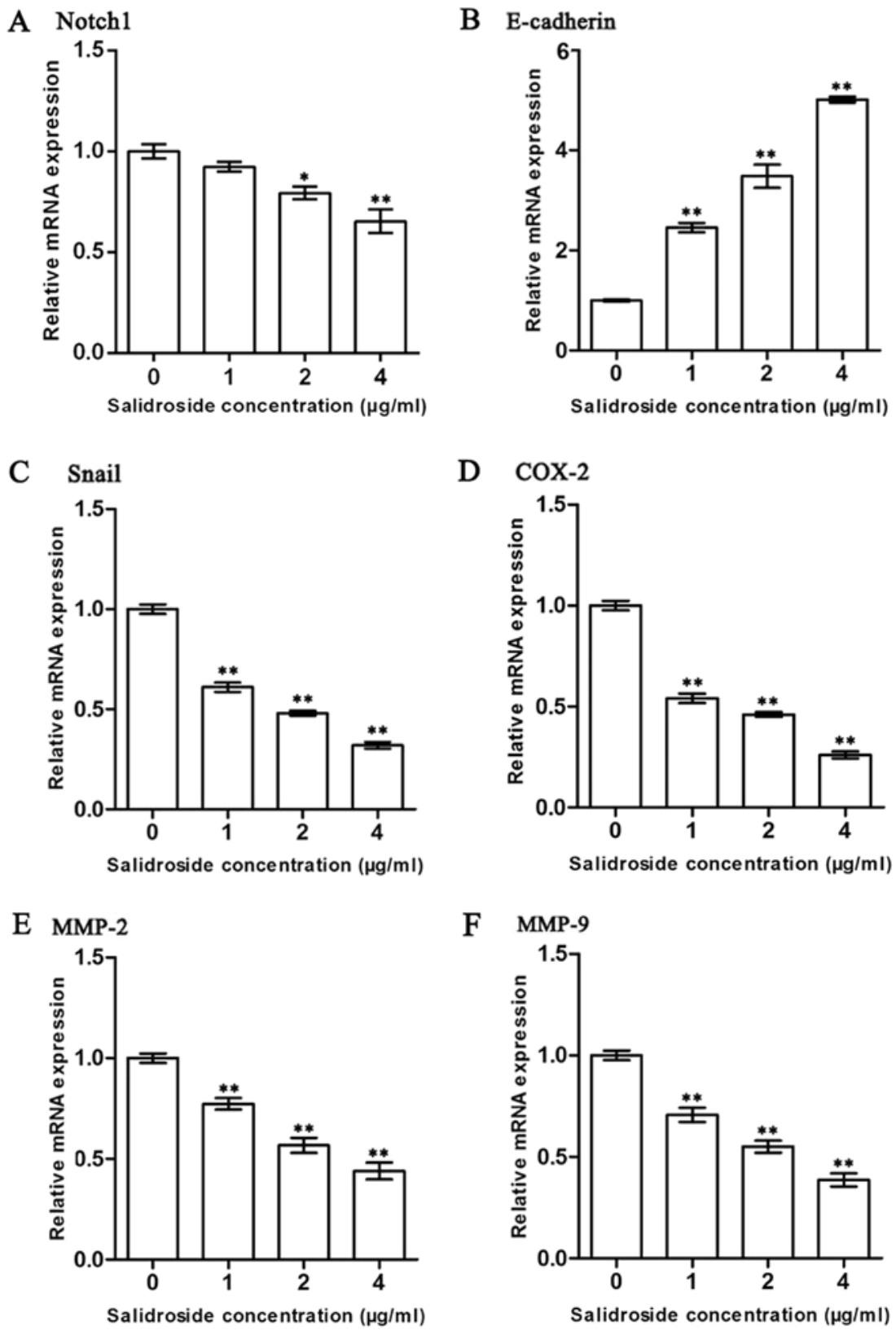

Figure 3. Effects of SDS on the expression of Notch1, Snail, COX-2, MMP-2, MMP-9 and E-cadherin in the HMCC97H cells. The cells were treated with 1, 2, and $4 \mu \mathrm{g} / \mathrm{ml}$ SDS. (A-F) The expression levels of Notchl, Snail, COX-2, MMP-2, MMP-9 and E-cadherin were measured by RT-qPCR, and the data were normalized to the $G A P D H$ gene as an internal control. Data are presented as the means \pm SEM from 3 independent experiments. Asterisks indicate statistically significant differences ( $\mathrm{P}<0.05$ and $\left.^{* *} \mathrm{P}<0.01\right)$ compared to the control $(0 \mu \mathrm{g} / \mathrm{ml})$. SDS, salidroside; COX-2, cyclooxygenase-2; MMP, matrix metalloproteinase; SEM, standard error of the mean.

$(\mathrm{P}<0.05)$. Moreover, E-cadherin expression was markedly increased following treatment with SDS $(\mathrm{P}<0.05)$.

SDS inhibits the activation of the Notch1 signaling pathway. Since the Notch1 signaling pathway is closely related to tumor metastasis and SDS can inhibit metastasis (49), we hypothesized that SDS may function through the Notch1 signaling pathway. The activity of the Notch signaling pathway was thus assessed by the expression of its downstream genes, including Heyl, Hesl and Hes5. As shown in Fig. 5, treatment with SDS significantly reduced the expression levels of these genes $(\mathrm{P}<0.05)$. This indicates that SDS likely inhibits the metastasis of cancer cells by halting the activation of the Notch1 signaling pathway.

\section{Discussion}

The Notch1 signaling pathway plays an important role in the differentiation, proliferation and apoptosis of cells during early development, and may eventually contribute to tumorigenesis $(50,51)$. Notch1 plays a paradoxical role in different types of cancer as it is upregulated in several types of tumors and plays complex roles in tumor development and metastasis (24-30). Previously, Notch1 expression has been shown to be associated with the decreased overall survival of patients with breast, colorectal and liver cancers $(31,52,53)$. SDS has been reported to display anticancer properties both in vivo and in vitro. A previous study demonstrated that SDS inhibited the migration and invasion of HT1080 cells (23). Considering 
A
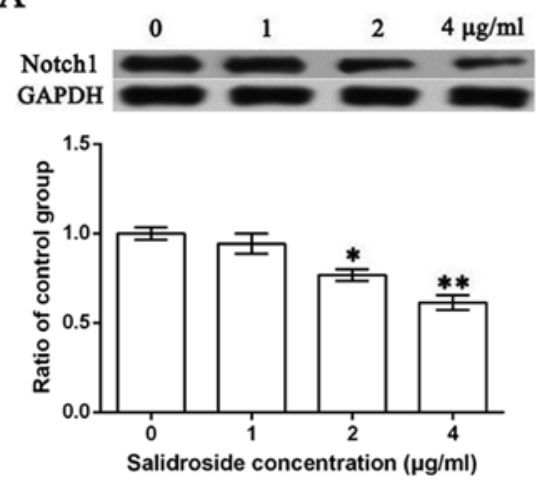

C
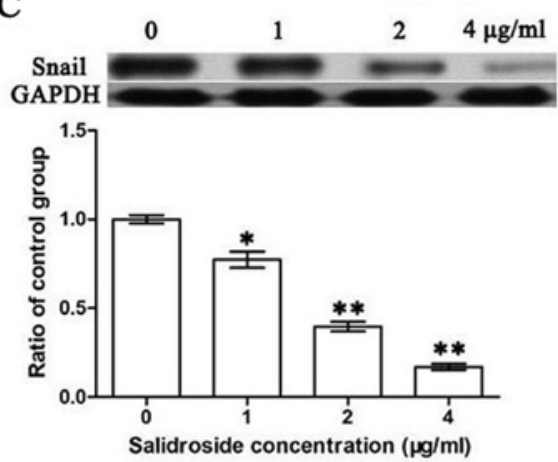

$\mathrm{E}$
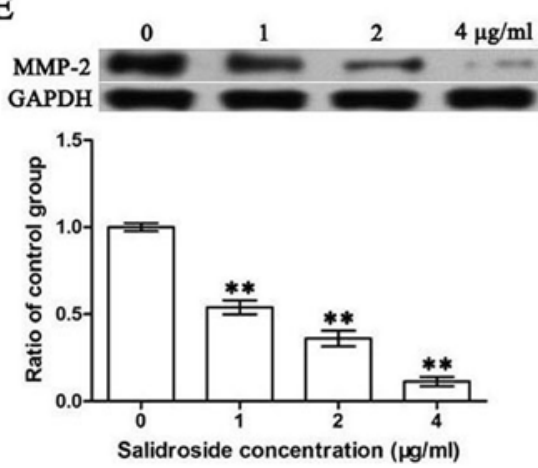

B
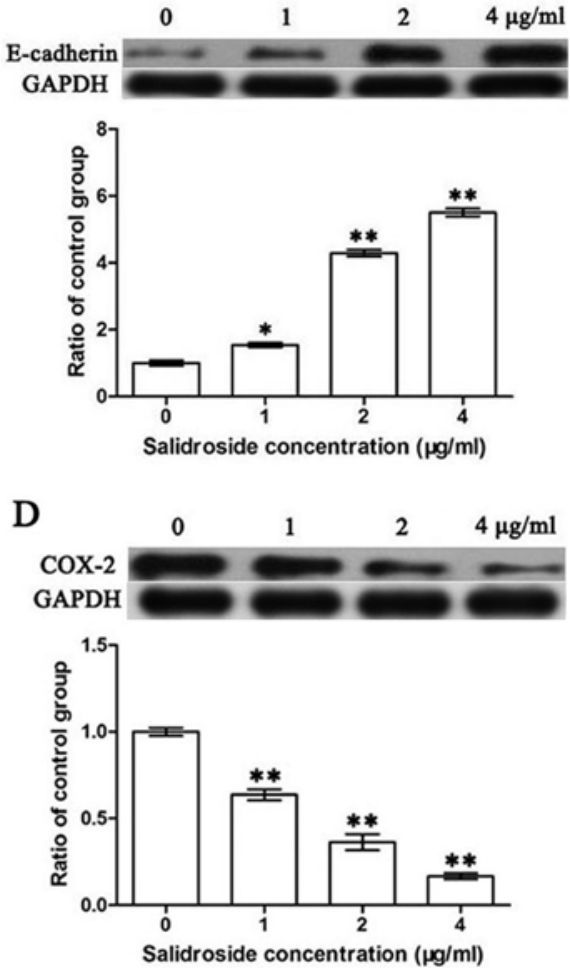

F
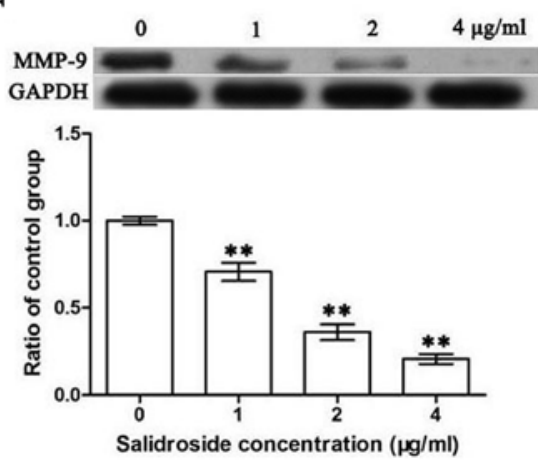

Figure 4. Effects of SDS on the expression of Notch1, Snail, COX-2, MMP-2, MMP-9 and E-cadherin in HMCC97H cells. The cells were treated with 1, 2 and $4 \mu \mathrm{g} / \mathrm{ml}$ SDS. (A-F) The protein expression levels of Notch1, Snail, COX-2, MMP-2, MMP-9 and E-cadherin were measured by western blot analysis. Bands were scanned and quantified and the results were normalized to GAPDH. Data are presented as the means \pm SEM from 3 independent experiments. Asterisks indicate statistically significant differences ( $\mathrm{P}<0.05$ and $\left.{ }^{* *} \mathrm{P}<0.01\right)$ compared to the control $(0 \mu \mathrm{g} / \mathrm{ml})$. SDS, salidroside; COX-2, cyclooxygenase-2; MMP, matrix metalloproteinase; SEM, standard errors of the mean.

the hepatoprotective role of Rhodiola rosea L. in traditional Chinese medicine, in the present study, we aimed to determine whether SDS can inhibit the metastasis of HCC via the Notch1 signaling pathway.

Tumor metastasis leads to the expression of two gene sets, including invasion promotors and invasion suppressors $(54,55)$. E-cadherin acts as a homotypic homophilic epithelial cell-cell adhesion molecule that can inhibit tumor cell invasion (37-39). During the invasion and metastasis of epithelial tumor cells mediated by Notch1, Snail expression is upregulated, while E-cadherin is downregulated. This indicates that Notch1 may mediate metastasis by disrupting the normal expression profiles of Snail and E-cadherin (33).

In the present study, we investigated the effects of SDS on the migration properties of highly invasive HCC cells via the scratch wound closure test and Transwell assay. The results from scratch wound closure assay revealed that wound closure was suppressed by SDS in a concentration-dependent manner (Fig. 1A). Similarly, the results of Transwell assay revealed that cell migration was suppressed by SDS in a concentration-dependent manner (Fig. 1B). This indicates that SDS can inhibit the migration of cancer cells in a concentration-dependent manner. In order to determine the possible underlying mechanisms, we detected the activity of the Notch1 signaling pathway. RT-qPCR was conducted to investigate the transcription of Notch1, the Notch1 signaling pathway relevant genes, Heyl, Hesl and Hes5, and the migration-associated genes, Snail, $C O X-2$ and E-cadherin, in HMCC97H cells. The expression levels of Notch1, Heyl, Hes1, Hes5, Snail and $C O X-2$ in the HMCC97Hcells were significantly decreased following treatment with SDS (Figs. 3 and 5). In addition, the expression of the migration-related gene, E-cadherin, in the HMCC97H cells was markedly increased following treatment with SDS (Fig. 3). Western blot analysis 


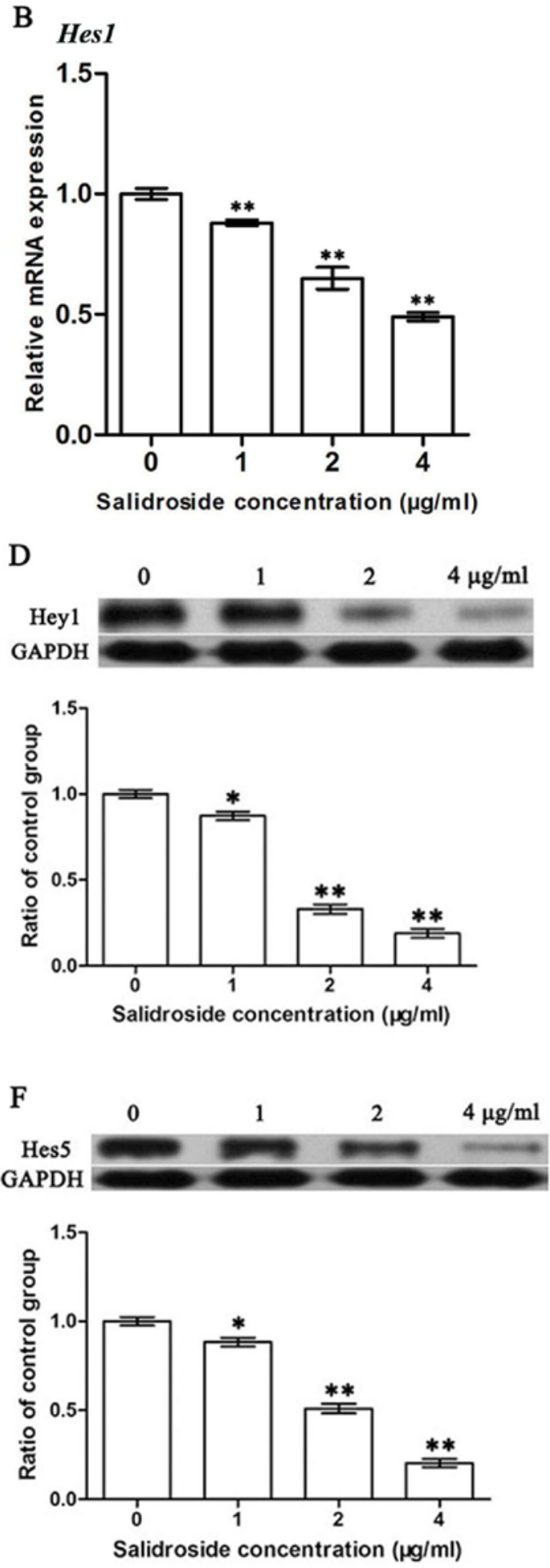

Figure 5. Effects of SDS on the expression of Heyl, Hesl and Hes 5 in HMCC97H cells. The cells were treated with 1, 2 and $4 \mu \mathrm{g} / \mathrm{ml}$ SDS. (A-C) The mRNA expression levels of Heyl, Hes 1 and Hes 5 were measured by RT-qPCR and the data were normalized to the GAPDH gene as an internal control. (D-F) Hey1, Hes1, and Hes5 protein expression levels were measured by western blot analysis. Bands were scanned and quantified and the results were normalized to GAPDH. Data are presented as the means \pm SEM from 3 independent experiments. Asterisks indicate statistically significant differences ( $\mathrm{P}<0.05$ and $\left.{ }^{* * *} \mathrm{P}<0.01\right)$ compared to the control $(0 \mu \mathrm{g} / \mathrm{ml})$. SDS, salidroside; Hes1, hairy and enhancer of split 1; Hes5, hairy and enhancer of split 5; Hey1, hairy/enhancer-of-split related with YRPW motif 1; RT-qPCR, reverse transcription-quantitative PCR; SEM, standard errors of the mean.

was also conducted to examine the protein expression levels of Notch1, Hey1, Hes1, Hes5, Snail, COX-2 and E-cadherin in the HMCC97H cells following treatment with SDS. SDS was found to significantly inhibit the activation of Notch1, Hey1, Hes1, Hes5, Snail and COX-2, while it markedly promoted the activation of E-cadherin (Figs. 4 and 5). These results indicate that SDS may suppress the migration of HMCC97H cells by inhibiting the activation of the Notch1 signaling pathway.

MMPs are a family of proteolytic enzymes that contribute to tumor cell invasion, migration and tumor angiogenesis by degrading the basement membrane and other ECM components (23,56-58). The endothelial cell activities, which 
are essential for new vessel development, can be blocked with MMP inhibitors. In return, MMP inhibitors likely halt the proliferation and invasion of tumor cells (59). Previously, the overexpression of tumor suppressor tissue inhibitors of metalloproteinases (TIMPs) was shown to downregulate the expression of MMP-2 and inhibit the invasion and metastasis of cancer cells (58). Previous studies have indicated that the Notch1 signaling pathway can regulate the activities of MMP-2 and MMP-9 in pancreatic cancer, lingual squamous cell carcinoma and breast cancer (28-30). In HCC cells, the downregulation of Notch1 decreases the expression and proteolytic activities of MMP-2 and MMP-9 (31). This suggests that the Notch1/MMP-2/MMP-9 axis may participate in tumor cell invasion. Previously, Sun et al demonstrated that the SDS decreased MMP-2 and MMP-9 activities, and inhibited the invasion of HT1080 cells (23); however, it remains unknown as to whether the SDS-attributed inhibition of MMP-2 and MMP-9 activities occurs via the Notch1 signaling pathway.

In this study, we examined the effects of SDS on the invasion of $\mathrm{HMCC} 97 \mathrm{H}$ cells, and also aimed to elucidate the underlying mechanisms. The results of Transwell assay revealed that SDS suppressed the invasion of $\mathrm{MHCC} 97 \mathrm{H}$ cells in a concentration-dependent manner, and the expression levels of MMP-2 and MMP-9 in the MHCC97H cells were significantly reduced following treatment with SDS. In addition, the expression levels of MMP-2 and MMP-9 in the MHCC97H cells were also reduced after SDS treatment. Previous studies have shown that Notch1 mediates the migration and invasion of tumor cells through regulation of MMP-2 and MMP-9 expression and that Notch1 signaling pathway activity can be suppressed with SDS treatment $(32,60)$. Therefore, SDS likely inhibits the migration and invasion of tumor cells by down-regulating the Notch1 signaling pathway.

In conclusion, the findings of this study suggest that SDS suppresses the migration and invasion of $\mathrm{HMCC} 97 \mathrm{H}$ cells in a concentration-dependent manner by inhibiting the activation of the Notch1 signaling pathway. The results suggest that SDS may be an effective anticancer agent with minimal adverse effects. Considering the importance of the Notch1 signaling pathway, this may be an excellent biomarker for the development of novel therapies for HCC; however, more profound research into the Notch1 signaling pathway and its role in cancer metastasis is required.

\section{Acknowledgements}

Not applicable.

\section{Funding}

The present study was supported by the Young Scientist Research Foundation of Medjaden Bioscience Limited (grant no. MJR20160051) and the National Natural Science Foundation of China (grant nos. 31770837 and 31800660).

\section{Availability of data and materials}

All data generated or analyzed during this study are included in this published article.

\section{Authors' contributions}

LL and SL conducted the experiment, LL, SL, and QD analyzed the data. LL and SL wrote the manuscript, YX designed the present study and revised the manuscript.

\section{Ethics approval and consent to participate}

Not applicable.

\section{Patient consent for publication}

Not applicable.

\section{Competing interests}

The authors declare that they have no competing interests.

\section{References}

1. Cabibbo G, Latteri F, Antonucci M and Craxì A: Multimodal approaches to the treatment of hepatocellular carcinoma. Nat Clin Pract Gastroenterol Hepatol 6: 159-169, 2009.

2. Singh S, Singh PP, Roberts LR and Sanchez W: Chemopreventive strategies in hepatocellular carcinoma. Nat Rev Gastroenterol Hepatol 11: 45-54, 2014

3. Dutta R and Mahato RI: Recent advances in hepatocellular carcinoma therapy. Pharmacol Ther 173: 106-117, 2017.

4. Yu Q, Liu ZY, Chen Q and Lin JS: Mcl-1 as a potential therapeutic target for human hepatocelluar carcinoma. J Huazhong Univ Sci Technolog Med Sci 36: 494-500, 2016.

5. Khanna K, Mishra KP, Ganju L and Singh SB: Golden root: A wholesome treat of immunity. Biomed Pharmacother 87: 496-502, 2017.

6. Hu X, Lin S, Yu D, Qiu S, Zhang X and Mei R: A preliminary study: The anti-proliferation effect of salidroside on different human cancer cell lines. Cell Biol Toxicol 26: 499-507, 2010.

7. Schriner SE, Abrahamyan A, Avanessian A, Bussel I, Maler S, Gazarian M, Holmbeck MA and Jafari M: Decreased mitochondrial superoxide levels and enhanced protection against paraquat in Drosophila melanogaster supplemented with Rhodiola rosea. Free Radic Res 43: 836-843, 2009.

8. Zhang L, Yu H, Sun Y, Lin X, Chen B, Tan C, Cao G and Wang Z: Protective effects of salidroside on hydrogen peroxide-induced apoptosis in SH-SY5Y human neuroblastoma cells. Eur J Pharmacol 564: 18-25, 2007.

9. Goel HC, Bala M,Prasad J, Singh S, Agrawala PK and Swahney RC: Radioprotection by Rhodiola imbricata in mice against whole-body lethal irradiation. J Med Food 9: 154-160, 2006.

10. Perfumi $M$ and Mattioli L: Adaptogenic and central nervous system effects of single doses of 3\% rosavin and $1 \%$ salidroside Rhodiola rosea L. extract in mice. Phytother Res 21: 37-43, 2007.

11. Spasov AA, Wikman GK, Mandrikov VB, Mironova IA and Neumoin VV: A double-blind, placebo-controlled pilot study of the stimulating and adaptogenic effect of Rhodiola rosea SHR-5 extract on the fatigue of students caused by stress during an examination period with a repeated low-dose regimen. Phytomedicine 7: 85-89, 2000.

12. Mishra KP,Padwad YS, Dutta A, Ganju L, Sairam M, Banerjee PK and Sawhey RC: Aqueous extract of Rhodiola imbricata rhizome inhibits proliferation of an erythroleukemic cell line $\mathrm{K}-562$ by inducing apoptosis and cell cycle arrest at G2/M phase. Immunobiology 213: 125-131, 2008.

13. Kang DZ, Hong HD, Kim KI and Choi SY: Anti-fatigue effects of fermented Rhodiola rosea extract in mice. Prev Nutr Food Sci 20: 38-42, 2015.

14. Tao K, Wang B, Feng D, Zhang W, Lu F, Lai J, Huang L, Nie T and Yang Q: Salidroside protects against 6-hydroxydopamine-induced cytotoxicity by attenuating ER stress. Neurosci Bull 32: 61-69, 2016.

15. Zhang Y, Yao Y, Wang H, Guo Y, Zhang H and Chen L: Effects of salidroside on glioma formation and growth inhibition together with improvement of tumor microenvironment. Chin J Cancer Res 25: 520-526, 2013. 
16. Wang H, Ding Y, Zhou J, Sun X and Wang S: The in vitro and in vivo antiviral effects of salidroside from Rhodiola rosea $\mathrm{L}$. against coxsackievirus B3. Phytomedicine 16: 146-155, 2009.

17. Ming DS, Hillhouse BJ, Guns ES, Eberding A, Xie S, Vimalanathan S and Towers GH: Bioactive compounds from Rhodiola rosea (Crassulaceae). Phytother Res 19: 740-743, 2005.

18. Wang J, Li JZ, Lu AX, Zhang KF and Li BJ: Anticancer effect of salidroside on A549 lung cancer cells through inhibition of oxidative stress and phospho-p38 expression. Oncol Lett 7: $1159-1164,2014$.

19. Hu X, Zhang X, Qiu S, Yu D and Lin S: Salidroside induces cell-cycle arrest and apoptosis in human breast cancer cells. Biochem Biophys Res Commun 398: 62-67, 2010.

20. Fan XJ, Wang Y, Wang L and Zhu M: Salidroside induces apoptosis and autophagy in human colorectal cancer cells through inhibition of PI3K/Akt/mTOR pathway. Oncol Rep 36: 3559-3567, 2016.

21. Senthilkumar R, Parimelazhagan T, Chaurasia OP and Srivastava RB: Free radical scavenging property and antiproliferative activity of Rhodiola imbricata Edgew extracts in HT-29 human colon cancer cells. Asian Pac J Trop Med 6: 11-19, 2013.

22. Zhao G, Shi A, Fan Z and Du Y: Salidroside inhibits the growth of human breast cancer in vitro and in vivo. Oncol Rep 33: 2553-2560, 2015.

23. Sun C, Wang Z, Zheng Q and Zhang H: Salidroside inhibits migration and invasion of human fibrosarcoma HT1080 cells. Phytomedicine 19: 355-363, 2012.

24. Gao J, Song Z, Chen Y, Xia L, Wang J, Fan R, Du R, Zhang F, Hong L, Song J, et al: Deregulated expression of Notch receptors in human hepatocellular carcinoma. Dig Liver Dis 40: 114-121, 2008

25. Nicolas M, Wolfer A, Raj K, Kummer JA, Mill P, van Noort M, Hui CC, Clevers H, Dotto GP and Radtke F: Notch1 functions as a tumor suppressor in mouse skin. Nat Genet 33: 416-421, 2003.

26. Sriuranpong V, Borges MW, Ravi RK, Arnold DR, Nelkin BD, Baylin SB and Ball DW: Notch signaling induces cell cycle arrest in small cell lung cancer cells. Cancer Res 61: 3200-3205, 2001.

27. Jang MS, Zlobin A, Kast WM and Miele L: Notch signaling as a target in multimodality cancer therapy. Curr Opin Mol Ther 2 : $55-65,2000$

28. Ma YC, Shi C, Zhang YN, Wang LG, Liu H, Jia HT, Zhang YX, Sarkar FH and Wang ZS: The tyrosine kinase c-Src directly mediates growth factor-induced Notch-1 and Furin interaction and Notch-1 activation in pancreatic cancer cells. PloS One 7: e33414, 2012

29. Yu B, Wei J, Qian X, Lei D, Ma Q and Liu Y: Notch1 signaling pathway participates in cancer invasion by regulating MMPs in lingual squamous cell carcinoma. Oncol Rep 27: 547-552, 2012.

30. Wang J, Fu L, Gu F and Ma Y: Notch1 is involved in migration and invasion of human breast cancer cells. Oncol Rep 26: $1295-1303,2011$

31. Zhou L, Zhang N, Li QJ, Sun W, Zhang Y, Wang DS and Dou KF Associations between high levels of Notch1 expression and high invasion and poor overall survival in hepatocellular carcinoma. Tumour Biol 34: 543-553, 2013.

32. Zhou L, Wang DS, Li QJ, Sun W, Zhang Y and Dou KF Downregulation of the Notch signaling pathway inhibits hepatocellular carcinoma cell invasion by inactivation of matrix metalloproteinase-2 and -9 and vascular endothelial growth factor. Oncol Rep 28: 874-882, 2012.

33. Sahlgren C, Gustafsson MV, Jin S, Poellinger L and Lendahl U: Notch signaling mediates hypoxia-induced tumor cell migration and invasion. Proc Natl Acad Sci USA 105: 6392-6397, 2008.

34. Wang XQ, Zhang W, Lui EL, Zhu Y, Lu P, Yu X, Sun J, Yang S, Poon RT and Fan ST: Notch1-Snaill-E-cadherin pathway in metastatic hepatocellular carcinoma. Int J Cancer 131 E163-E172, 2012.

35. Lim SO, Kim HS, Quan X, Ahn SM, Kim H, Hsieh D, Seong JK and Jung G: Notch1 binds and induces degradation of Snail in hepatocellular carcinoma. BMC Biol 9: 83, 2011.

36. Lim SO, Park YM, Kim HS, Quan X, Yoo JE, Park YN, Choi GH and Jung G: Notch1 differentially regulates oncogenesis by wildtype p 53 overexpression and p 53 mutation in grade III hepatocellular carcinoma. Hepatology 53: 1352-1362, 2011.

37. Khamis ZI, Iczkowski KA and Sang QXA: Metastasis suppressors in human benign prostate, intraepithelial neoplasia, and invasive cancer: Their prospects as therapeutic agents. Med Res Rev 32: 1026-1077, 2012

38. Debruyne P, Vermeulen $\mathrm{S}$ and Mareel M: The role of the E-cadherin/catenin complex in gastrointestinal cancer. Acta Gastroenterol Belg 62: 393-402, 1999.
39. Mareel M, Vleminckx K, Vermeulen S, Yan G, Bracke M and van Roy F: Downregulation in vivo of the invasion-suppressor molecule E-cadherin in experimental and clinical cancer. Princess Takamatsu Symp 24: 63-80, 1994.

40. Vihinen $P$ and Kähäri VM: Matrix metalloproteinases in cancer: Prognostic markers and therapeutic targets. Int J Cancer 99: 157-166, 2002

41. Curran S and Murray GI: Matrix metalloproteinases: Molecular aspects of their roles in tumour invasion and metastasis. Eur J Cancer 36: 1621-1630, 2000.

42. Stetler-Stevenson WG: The role of matrix metalloproteinases in tumor invasion, metastasis, and angiogenesis. Surg Oncol Clin N Am 10: 383-392, 2001

43. Weis M, Heeschen C, Glassford AJ and Cooke JP: Statins have biphasic effects on angiogenesis. Circulation 105: 739-745, 2002

44. Wu HM, Zhu SL, He LJ, Liu YH and Xie D: Clinical significance of macrophage migration inhibitory factor in invasion of ovarian cancer. Chin J Cancer 28: 1054-1060, 2009. [Clinical significance of macrophage migration inhibitory factor in invasion of ovarian cancer].

45. Livak KJ and Schmittgen TD: Analysis of relative gene expression data using real-time quantitative PCR and the 2(-Delta Delta C(T)) Method. Methods 25: 402-408, 2001.

46. Wang Y, Shi J, Chai K, Ying X and Zhou BP: The role of Snail in EMT and tumorigenesis. Curr Cancer Drug Targets 13: 963-972, 2013.

47. Qu L and Liu B: Cyclooxygeanse-2 promotes metastasis in osteosarcoma. Cancer Cell Int 15: 69, 2015.

48. Onder TT, Gupta PB, Mani SA, Yang J, Lander ES and Weinberg RA: Loss of E-cadherin promotes metastasis via multiple downstream transcriptional pathways. Cancer Res 68: 3645-3654, 2008

49. Wieland E, Rodriguez-Vita J, Liebler SS, Mogler C, Moll I, Herberich SE, Espinet E, Herpel E, Menuchin A, Chang-Claude J, et al: Endothelial Notch1 activity facilitates metastasis. Cancer Cell 31: 355-367, 2017.

50. Egan SE, St-Pierre B and Leow CC: Notch receptors, partners and regulators: From conserved domains to powerful functions. Curr Top Microbiol Immunol 228: 273-324, 1998.

51. Callahan R and Egan SE: Notch signaling in mammary development and oncogenesis. J Mammary Gland Biol Neoplasia 9: 145-163, 2004.

52. Reedijk M, OdorcicS, Chang L, Zhang H,MillerN, McCready DR, Lockwood G and Egan SE: High-level coexpression of JAG1 and NOTCH1 is observed in human breast cancer and is associated with poor overall survival. Cancer Res 65: 8530-8537, 2005.

53. Chu D, Li Y, Wang W, Zhao Q, Li J, Lu Y, Li M, Dong G, Zhang H, $\mathrm{Xie} \mathrm{H}$ and Ji G: High level of Notch1 protein is associated with poor overall survival in colorectal cancer. Ann Surg Oncol 17: $1337-1342,2010$

54. Makrilia N, Kollias A, Manolopoulos L and Syrigos K: Cell adhesion molecules: Role and clinical significance in cancer. Cancer Invest 27: 1023-1037, 2009.

55. Mareel M, Vleminckx K, Vermeulen S, Bracke M and Van Roy F: E-cadherin expression: A counterbalance for cancer cell invasion. Bull Cancer 79: 347-355, 1992.

56. Shimada T, Nakamura H, Yamashita K, Kawata R, Murakami Y, Fujimoto N, Sato H, Seiki M and Okada Y: Enhanced production and activation of progelatinase A mediated by membrane-type 1 matrix metalloproteinase in human oral squamous cell carcinomas: Implications for lymph node metastasis. Clin Exp Metastasis 18: 179-188, 2000

57. Rajoria S, Suriano R, George A, Shanmugam A, Schantz SP, Geliebter J and Tiwari RK: Estrogen induced metastatic modulators MMP-2 and MMP-9 are targets of 3,3'-diindolylmethane in thyroid cancer. PLoS One 6: e15879, 2011.

58. Yan L, Lin B, Gao L, Gao S, Liu C, Wang C, Wang Y, Zhang S and Iwamori M: Lewis (y) antigen overexpression increases the expression of MMP-2 and MMP-9 and invasion of human ovarian cancer cells. Int J Mol Sci 11: 4441-4452, 2010.

59. Murphy AN, Unsworth EJ and Stetler-Stevenson WG: Tissue inhibitor of metalloproteinases-2 inhibits bFGF-induced human microvascular endothelial cell proliferation. J Cell Physiol 157: 351-358, 1993.

60. Zhao HB, Qi SN, Dong JZ, Ha XQ, Li XY, Zhang QW, Yang YS, Bai $J$ and Zhao L: Salidroside induces neuronal differentiation of mouse mesenchymal stem cells through Notch and BMP signaling pathways. Food Chem Toxicol 71: 60-67, 2014. 